\title{
Ultrastructure, Serogrouping and Localization of Surface Antigens of Bacteroides intermedius
}

\author{
By DEIRDRE A. DEVINE, ${ }^{1}$ RUDOLF GMÜR ${ }^{2}$ AND \\ PAULINE S. HANDLEY ${ }^{* *}$ \\ ${ }^{1}$ Department of Cell and Structural Biology, Stopford Building, Manchester University, \\ Oxford Road, Manchester M13 9PT, UK \\ ${ }^{2}$ Department of Oral Microbiology and General Immunology, Dental Institute, \\ University of Zurich, $\mathrm{CH}-8028$ Zurich, Switzerland
}

(Received 2 November 1988; revised 19 December 1988; accepted 9 January 1989)

\begin{abstract}
The surface ultrastructure of 21 strains of Bacteroides intermedius was investigated by electron microscopy. Rat monoclonal antibodies ( $\mathrm{mAbs}$ ) were used to define serogroups and to detect the location of surface antigens. All 21 isolates had capsules as demonstrated by the use of wet and dry Indian ink stains. Negative staining of whole cells with $1 \%(\mathrm{w} / \mathrm{v})$ methylamine tungstate showed that all 21 isolates carried clumped peritrichous fibrils with strain dependent morphology, density and length $(\leqslant 0.75 \mu \mathrm{m})$. Fibrils on 11 of 13 fresh clinical isolates were more conspicuously clumped and easily visible, whereas those on 6 of 8 laboratory strains were indistinct and were at the limits of the resolution of the negative staining technique. Staining with ruthenium red (RR), followed by thin sectioning, revealed a dense, amorphous $R R$ staining layer (RRL), up to $24.8 \pm 3.0 \mathrm{~nm}$ thick, adjacent to the outer membrane on all of 15 strains examined. All isolates had a less dense RR staining matrix (RRM) extending away from the RRL. The structure of the RRM varied between strains. Four rat mAbs (37BI6.1, $38 \mathrm{BI} 1,39 \mathrm{BI} 1.1$ and $40 \mathrm{BI} 3.2$ ) were used to serogroup the 21 strains of $B$. intermedius. Immunonegative staining revealed that the $\mathrm{mAbs}$ were not directed against fibrils. Antigens recognized by mAb 37BI6.1 and $\mathrm{mAb} 39 \mathrm{BI} 1.1$ were located on the surfaces of cells, beneath fibrils, and on extracellular vesicles. $\mathrm{mAb} 38 \mathrm{BI}$ recognized an antigen which was most accessible on lysed cells, and non-specific binding of mAb 40BI3.2 to grids prevented its localization on the cell surface.
\end{abstract}

\section{INTRODUCTION}

Bacteroides intermedius can be isolated from both healthy and diseased human subgingival sites, and there is a growing body of evidence implicating it as a potential causative agent of periodontal disease (Slots, 1979, 1986; Zambon et al., 1981; Moore et al., 1985). The precise role of $B$. intermedius in this process remains unclear. However, its ability to colonize the subgingival area, whether by adhering to host tissue or to other bacterial members of the subgingival microflora, is likely to play a significant part in determining its pathogenic potential. It has been suggested that surface components such as fimbriae, capsules and lipopolysaccharides may be important in the adhesion of bacteria to oral surfaces (Slots \& Genco, 1984; Mayrand \& Holt, 1988).

Little is known about the surface properties of $B$. intermedius. Some studies have indicated that surface structures detected by electron microscopy differ between oral black-pigmented Bacteroides species (Listgarten \& Lai, 1979; Woo et al., 1979; Okuda et al., 1981; Handley \&

\footnotetext{
Abbreviations: BS, borate buffered saline; mAb, monoclonal antibody; RR, ruthenium red; RRL, ruthenium red staining layer; RRM, ruthenium red staining matrix.
} 
Tipler, 1986). Listgarten \& Lai (1979) suggested that the morphological differences they observed may be useful to differentiate between certain species or subspecies, and Okuda $\mathrm{et}$ al. (1981) proposed that such differences may lead to species interacting differently with mammalian cells. These studies have usually examined only one or two strains of $B$. intermedius. Yamamoto et al. (1982) found that not all of nine strains of $B$. intermedius examined possessed 'pili-like' structures, as visualized by negative staining. However, it is probable that their negative staining technique failed to reveal all these structures, as more strains carried them when viewed in shadowed preparations. Handley \& Tipler (1986) described the dense masses of peritrichous fibres seen on two strains of $B$. intermedius, and some other Bacteroides species, as fibrils; these were distinct from fimbriae in that they clumped copiously and had no measurable width.

Staining of some Bacteroides spp. with ruthenium red (RR) has been used to visualize polyanionic surface components, probably acidic polysaccharides (Luft, 1971), but these have usually included only a few strains of $B$. intermedius (Woo et al., 1979; Okuda et al., 1981). Yamamoto et al. (1982), however, found that the appearance of the RR staining layer (RRL) of $B$. intermedius varied between strains.

In addition to these ultrastructural differences, antigenic heterogeneity in $B$. intermedius has been reported (Gmür \& Guggenheim, 1983; Gmür \& Wyss, 1985), and B. intermedius isolates have been divided into three serogroups, which may be correlated with genotype (Gmür \& Wyss, 1985). The ultrastructural localization of the antigens used in serogrouping is unknown.

As previously mentioned, it has been suggested that some surface components may be important in the adhesion of bacteria to oral surfaces (Slots \& Genco, 1984; Mayrand \& Holt, 1988). Also, these cell components have the potential to determine host antibody response and the susceptibility of bacteria to complement and phagocytosis. A survey of the surface ultrastructure of a larger number of $B$. intermedius strains would characterize the species more completely, and would form a basis for future studies aimed towards understanding the adhesive and other surface properties of the organism. Therefore, in this study the surface ultrastructure of 21 strains of $\boldsymbol{B}$. intermedius was examined. In addition, the serogroup of each strain was determined, and the structural location of the antigens used in serogrouping was investigated by immunoelectron microscopy.

\section{METHODS}

Bacterial strains. Twenty-one isolates of $B$. intermedius were studied. Six strains were included in a previous study (Gmür \& Wyss, 1985). Of these, strains OMZ 227 (M107-74), OMZ 248, OMZ 326 (FDC 581) and OMZ 327 (FDC 377) were originally isolated from subgingival plaque. Strain OMZ 277 (ATCC 25261) was isolated from a laryngotomy wound, and $\mathrm{OMZ} 311(3 \mathrm{~b})$ was isolated from an unspecified oral site. Strains BH 18/23 and BH 20/30, periodontal pocket and supragingival plaque isolates respectively, were provided by G. Bowden (Department of Oral Biology, University of Manitoba, Canada). These eight organisms have been isolated for a number of years, and some are well recognized reference strains; they will all be referred to as laboratory strains. Thirteen recently isolated clinical strains were also included for study. These were isolated from periodontal pockets of adults with rapidly progressing periodontitis and were provided by D. B. Drucker (Department of Cell and Structural Biology, University of Manchester, UK). All strains were confirmed as B. intermedius with the API $20 \mathrm{~A}$ identification kit.

Growth conditions. All strains were grown in modified FUM medium (Gmür \& Guggenheim, 1983), which was prepared and sterilized as described by Loesche et al. (1972). FUM contained (per litre of distilled water): $10 \mathrm{~g}$ tryptone, $5 \mathrm{~g}$ yeast extract, $3 \mathrm{~g}$ glucose, $2 \mathrm{mg}$ haemin, $1 \mathrm{mg}$ menadione, $0.5 \mathrm{~g}$ cysteine. $\mathrm{HCl}, 0.9 \mathrm{~g} \mathrm{NaCl}, 0.5 \mathrm{~g}$ $\mathrm{Na}_{2} \mathrm{CO}_{3}, 1 \mathrm{~g} \mathrm{KNO}_{3}, 0.45 \mathrm{~g} \mathrm{KH}_{2} \mathrm{PO}_{4}, 0.45 \mathrm{~g} \mathrm{~K}_{2} \mathrm{HPO}_{4}, 0.9 \mathrm{~g}\left(\mathrm{NH}_{4}\right)_{2} \mathrm{SO}_{4}, 0.188 \mathrm{~g} \mathrm{MgSO}_{4} .7 \mathrm{H}_{2} \mathrm{O}$, and had a pH of $7 \cdot 1$. After sterilization, $5 \%(\mathrm{v} / \mathrm{v})$ sterile horse serum was added. Columbia agar base (Oxoid $\mathrm{CM} 311$ ) supplemented with $5 \%(\mathrm{v} / \mathrm{v})$ horse blood was used as a solid medium. For all procedures, $1 \mathrm{ml}$ of an overnight broth culture was transferred to $9 \mathrm{ml}$ fresh FUM, which was incubated for no more than $48 \mathrm{~h}$. Cultures were grown in prereduced media at $37{ }^{\circ} \mathrm{C}$ in a Don Whitley anaerobic cabinet (mark II) under an atmosphere of $80 \% \mathrm{~N}_{2}, 10 \% \mathrm{H}_{2}$ and $10 \%$ $\mathrm{CO}_{2}$. All strains of $B$. intermedius were stored in glycerol at $-70^{\circ} \mathrm{C}$.

Capsule detection. Capsules were detected by negative staining with Indian ink. A broth suspension of bacteria was mixed on a glass slide with $10 \%(\mathrm{w} / \mathrm{v})$ glucose solution and a drop of Indian ink. This mixture was spread thinly across the surface of the slide, allowed to dry, fixed with ethanol and stained with ammonium crystal violet. 
Wet films were also prepared by mixing the bacterial suspension with $10 \%(w / v)$ glucose and Indian ink on a glass slide, placing a coverslip on the mixture and then blotting out the excess. Bacteria were examined using a Leitz Dialux 20 light microscope.

Negative staining for electron microscopy. Cultures of $B$. intermedius, grown for up to $48 \mathrm{~h}$ in FUM medium, were washed twice in water and were stained using the method described by Handley \& Tipler (1986). The washed suspensions were placed on Formvar covered copper grids ( 400 mesh, Agar Aids) which had been carbon-coated and plasma-glowed in a Nanotech $300 \mathrm{~S}$ coating unit. Bacteria were then negatively stained with $1 \%(\mathrm{w} / \mathrm{v})$ methylamine tungstate (EMscope Laboratories) or $1 \%(\mathrm{w} / \mathrm{v})$ ammonium molybdate (Agar Aids). Micrographs were taken on a Hitachi 600 electron microscope.

Ruthenium red staining. A modification of the method described by Luft (1971) was used to visualize polyanionic components associated with the surface of $B$. intermedius. Cultures grown for $16-48 \mathrm{~h}$ in FUM medium were washed three times in $0.2 \mathrm{M}$-sodium cacodylate buffer $(\mathrm{pH} \mathrm{7.3)}$ and were resuspended in a mixture containing equal volumes of $0.2 \mathrm{M}$-cacodylate buffer ( $\mathrm{pH} \mathrm{7.3),3.6 \% (v/v)} \mathrm{glutaraldehyde,} \mathrm{and} \mathrm{a} \mathrm{solution} \mathrm{of} \mathrm{RR}\left(10 \mathrm{mg} \mathrm{ml}^{-1}\right.$, 1500 p.p.m.). Fixation in this mixture took place on a rotating turntable for $1 \mathrm{~h}$ at room temperature. Following three further washes in $0.2 \mathrm{M}$-cacodylate buffer ( $\mathrm{pH} \mathrm{7.3)}$, bacteria were resuspended in equal volumes of $4 \%$ ( $/ \mathrm{v} / \mathrm{v})$ osmium tetroxide, $0.2 \mathrm{M}$-cacodylate buffer $(\mathrm{pH} \mathrm{7.3)}$ ) and RR, and were rotated overnight at room temperature. The suspensions were then washed three times in $0.2 \mathrm{M}$-cacodylate buffer $(\mathrm{pH} \mathrm{7.3)}$ and were dehydrated through a graded series of ethanol, with concentrations ranging from $30 \%(\mathrm{v} / \mathrm{v})$ to $100 \%(\mathrm{v} / \mathrm{v})$. Controls were prepared by replacing RR with distilled water throughout the procedure. Specimens were embedded in LR White resin (London Resin Co.) and sections cut on a Reichert OMU4 ultramicrotome. Thin sections of control preparations were post-stained with a saturated solution of uranyl acetate in $50 \%(\mathrm{v} / \mathrm{v})$ aqueous alcohol, and lead citrate (Reynolds, 1963). Micrographs were taken on a Hitachi 600 electron microscope.

ELISA. The whole cell ELISA technique described by Gmür \& Guggenheim (1983) was used to determine the antigenic reactivity groups of the 21 strains of $B$. intermedius. Hybridoma culture supernatants of rat monoclonal antibodies (mAbs) 37BI6.1, 38BI1, 39BI1 .1 and 40BI3.2 (mAb37, mAb38, mAb39 and mAb40) were stored at $-20^{\circ} \mathrm{C}$. B. intermedius strains were grown in FUM for $16-48 \mathrm{~h}$ and were washed twice in $0.9 \%(\mathrm{w} / \mathrm{v}) \mathrm{NaCl}$. They were resuspended in phosphate buffered saline $(\mathrm{pH} 7 \cdot 2)$ to an optical density at $550 \mathrm{~nm}$ of $0 \cdot 5\left(2-3 \times 10^{8}\right.$ organisms $\left.\mathrm{ml}^{-1}\right)$. Flat-bottomed microtitre plates were pretreated for $30 \mathrm{~min}$ at room temperature with $0 \cdot 1 \mathrm{ml} 0 \cdot 1 \%(\mathrm{v} / \mathrm{v})$ glutaraldehyde in borate buffered saline (BS: $0.14 \mathrm{M}$-boric acid, $0.025 \mathrm{M}$-sodium tetraborate, $0.075 \mathrm{M}-\mathrm{NaCl}$, pH 8.1). Bacterial suspension $(0 \cdot 2 \mathrm{ml})$ was added to each well and the plates were centrifuged for $20 \mathrm{~min}$ at $1300 \mathrm{~g}$. The bound bacteria were then fixed by the addition of $0.1 \mathrm{ml} 0.1 \%(\mathrm{v} / \mathrm{v})$ glutaraldehyde in BS for $30 \mathrm{~min}$ at room temperature. The plates were washed twice with $\mathrm{BS}$ and were stored at $4{ }^{\circ} \mathrm{C}$, after the addition to each well of $0.2 \mathrm{ml}$ BS containing $0 \cdot 1 \%(\mathrm{w} / \mathrm{v})$ bovine serum albumin.

mAbs were diluted in BS containing $0.5 \%(\mathrm{w} / \mathrm{v})$ bovine serum albumin and $0.05 \%(\mathrm{v} / \mathrm{v})$ Tween 20 . The initial dilution was 1 in 10 followed by serial doubling dilutions up to 1 in 10240. Antigen-coated microtitre plates were washed twice with BS and $0.2 \mathrm{ml}$ of the appropriate mAb dilution was added. After incubation at $4{ }^{\circ} \mathrm{C}$ overnight the wells were washed four times with ELISA wash solution $(0.9 \%, \mathrm{w} / \mathrm{v}, \mathrm{NaCl}$ plus $0.05 \%, \mathrm{v} / \mathrm{v}, \mathrm{Tween} 20)$. Horseradish-peroxidase-conjugated rabbit anti-rat IgG (P+S Biochemicals) was diluted 1 in 2000 in BS containing $0.5 \%(\mathrm{w} / \mathrm{v})$ bovine serum albumin and $0.05 \%(\mathrm{v} / \mathrm{v})$ Tween 20 , and $0.1 \mathrm{ml}$ was added to each well. The plates were incubated at $37^{\circ} \mathrm{C}$ for 90 min following which they were washed eight times with ELISA wash solution, and the wells were filled with $0.2 \mathrm{ml}$ ELISA substrate solution $(3.7 \mathrm{mM}-1,2$-phenylene-diamine, $0.012 \%$, $\mathrm{v} / \mathrm{v}, \mathrm{H}_{2} \mathrm{O}_{2}$ in $24.3 \mathrm{~mm}$-citric acid, $25.7 \mathrm{~mm}-\mathrm{Na}_{2} \mathrm{HPO}_{4}$, pH 5.1). After incubation in the dark at room temperature, $0.05 \mathrm{ml} 2.5 \mathrm{M}-\mathrm{H}_{2} \mathrm{SO}_{4}$ was added to each well to stop the reaction, and the highest dilution of mAb producing a detectable colour reaction was recorded.

Immunonegative staining. FUM cultures (16-24 h) of $B$. intermedius strains OMZ 227, OMZ 248, OMZ 277, BH 18/23, MUI 32, MUI 41, MUI 44, MUI 57 and MUI 65 were washed twice in BS containing $0 \cdot 5 \%(w / v)$ bovine serum albumin and $0.05 \%(\mathrm{v} / \mathrm{v})$ Tween $20, \mathrm{pH} 8.6$. The same buffer solution was used to dilute the mAbs. Bacteria were placed on Formvar covered nickel grids ( 400 mesh, Agar Aids) which had been carbon-coated and plasma-glowed in a Nanotech $300 \mathrm{~S}$ coating unit. For all further treatments and washings the grids were suspended upside-down on $0.02 \mathrm{ml}$ drops of the appropriate solution, which had been placed on a strip of Parafilm. The grids were first treated for $5 \mathrm{~min}$ with BS containing $0.5 \%(\mathrm{w} / \mathrm{v})$ bovine serum albumin and $0.05 \%(\mathrm{v} / \mathrm{v})$ Tween 20 . They were blotted and were then placed on a drop of $\mathrm{mAb}$ dilution, usually 1 in 5 or 1 in 10, and binding took place for 30 min at room temperature. The grids were washed in buffer five times, blotting between each wash. Goat anti-rat IgG conjugated to $10 \mathrm{~nm}$ gold particles (Janssen) was diluted 1 in 10 in BS containing $0.5 \%(\mathrm{w} / \mathrm{v})$ bovine serum albumin and $0.05 \%(\mathrm{v} / \mathrm{v})$ Tween 20, and the grids were suspended on this solution for $30 \mathrm{~min}$. Following five washes in water, the grids were stained with $1 \%(\mathrm{w} / \mathrm{v})$ methylamine tungstate. Controls were run in which the $\mathrm{mAb}$ was replaced by buffer. Some strains were also tested against mAbs with which they had not reacted in the ELISA system. Micrographs were taken on a Hitachi 600 electron microscope. 


\section{RESULTS}

\section{Capsule production}

All of the $21 \mathrm{~B}$. intermedius isolates were capsulate when examined in both dry and wet Indian ink preparations. Capsule sizes ranged from equal to the cell width to about three times the cell width. No bacterial cells without capsules were detected, although the coarseness of the Indian ink stain, combined with the poor staining of many of these strains with crystal violet, may have made non-capsulate cells difficult to see. Capsules were detected on cells in the exponential and stationary phases of growth.

\section{Negative staining for electron microscopy}

The structures seen on $\boldsymbol{B}$. intermedius strains are defined as fibrils. These have no measurable width along their length as they clump together, often producing a tapered appearance, and individual fibrils are rarely observed (Handley \& Tipler, 1986). They are distinct from fimbriae, which have a measurable width (3-14 nm) and a variable length of up to $20 \mu \mathrm{m}$ (Ottow, 1975). Fibril production by the strains examined in this study did not appear to be subject to phase variation and, unless otherwise stated, the results discussed are those for 16-24 h cultures which were in the early to mid-stationary growth phase.

All 21 isolates of $B$. intermedius screened in this study carried peritrichous, usually flexible, clumped fibrils. However, the density, length and ultrastructure of the fibrils were strain dependent.

Thirteen isolates (OMZ 277, BH 18/23 and 11 of the 13 fresh clinical isolates) had very clumped, easily detectable, peritrichous fibrils (Fig. $1 a$ ). All cells in a population were fibrillar. Fig. $1(a)$ demonstrates the copious clumping of these fibrils, and their subsequent splaying out, producing tapered structures whose ends could not be seen clearly. Thus, fibril length was difficult to measure accurately. The longest fibrils detected were on strain MUI 77 (Fig. $1 a$ ) and were up to $0.75 \mu \mathrm{m}$ long.

Fibrils between adjacent cells of $B$. intermedius strains frequently interacted in the way seen in Fig. $1(b)$. They were stretched between cells and were apparently fused.

The remaining eight isolates of $B$. intermedius (OMZ 227, OMZ 248, OMZ 311, OMZ 326, OMZ 327, BH 20/30, MUI 1 and MUI 65) produced fibrils which appeared indistinct against the background stain, lacked structure and showed less tendency to clump together (Fig. $1 c$, strain OMZ 227). These fibrils were easily discernible on heavily stained cells, but were difficult to see when staining was light. Therefore, it was impossible to detect if all cells carried fibrils. In addition, staining the same cultures with $1 \%(\mathrm{w} / \mathrm{v})$ ammonium molybdate often failed to reveal surface structures on any cells in a population.

Neither the type of fibril produced, nor fibril length appeared to be related to capsule width. All isolates produced extracellular vesicles (Fig. 1). When grown in FUM for 16-24 h most strains produced few of them. By $48 \mathrm{~h}$, vesicle production had increased markedly, and broth cultures had usually lost viability. Fibrils could be seen attached to large extracellular vesicles, but were rarely seen free in areas surrounding bacterial cells.

Ruthenium red staining. Fifteen isolates were fixed and stained with $R R$ before thin sectioning. All strains carried an amorphous, electron dense RRL adjacent to the outer membrane, shown clearly in Fig. 2(a). On a few isolates this layer was indistinct (Fig. 2b) and was thus difficult to measure. On the remaining isolates the width of the RRL varied between strains, and ranged from $15.8 \pm 1.9 \mathrm{~nm}$ on strain MUI 44 to $24.8 \pm 3.0 \mathrm{~nm}$ on strain MUI 24 .

Fig. 1. Negative staining of whole cells of $B$. intermedius with $1 \%(w / v)$ methylamine tungstate. (a) B. intermedius MUI 77. This clinical isolate carries dense, peritrichous, clumped fibrils extending up to $0.75 \mu \mathrm{m}$ from the cell surface. (b) B. intermedius MUI 32 carries similar fibrils to MUI 77 , and they can be seen extending between adjacent cells, apparently fused together. $(c) B$. intermedius $\mathrm{OMZ} 227$ : a laboratory strain carrying peritrichous fibrils (arrowed) which are difficult to resolve and are most visible in areas of darker stain. All strains produced extracellular vesicles. All bar markers represent $100 \mathrm{~nm}$. 

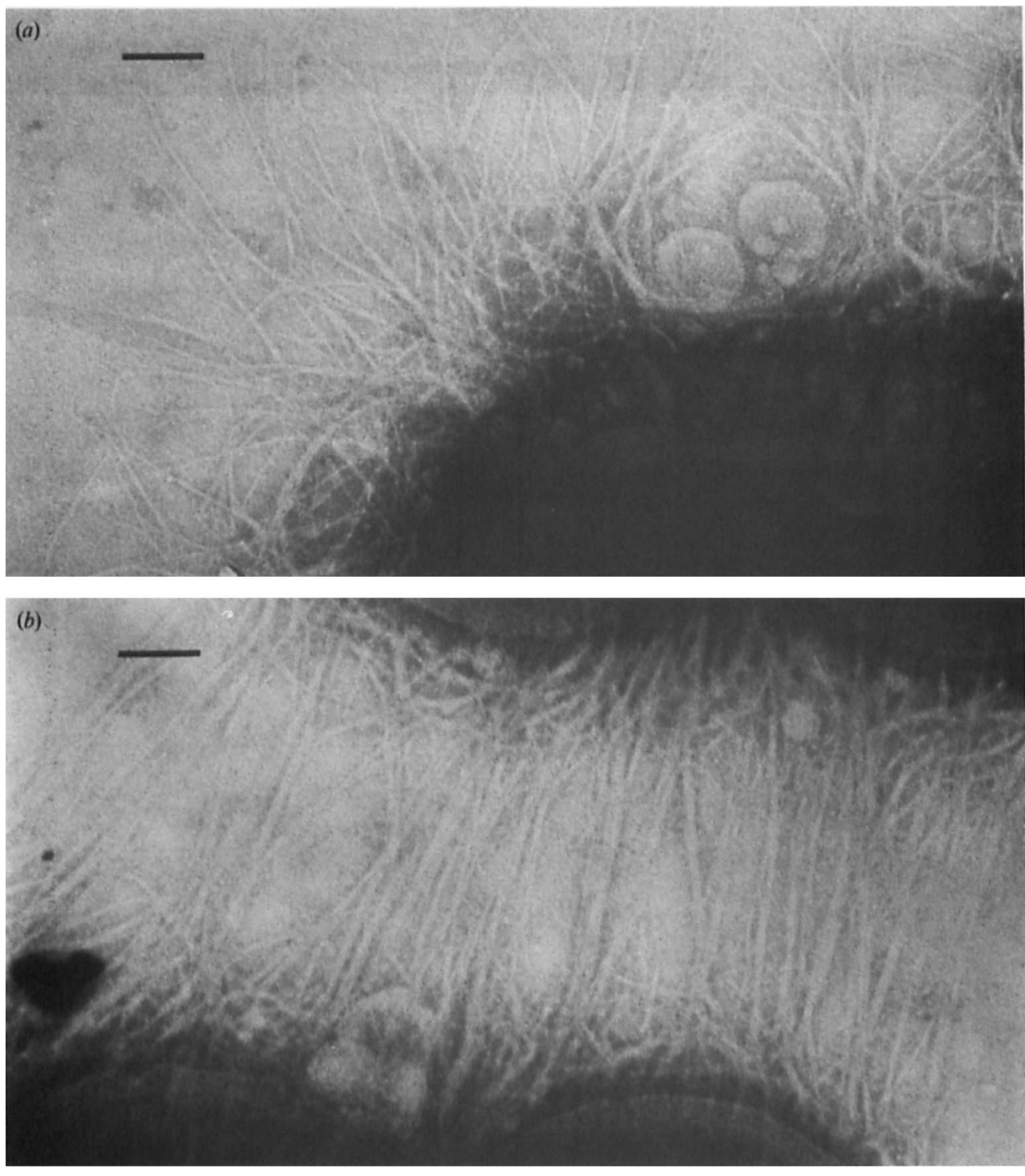

(c)

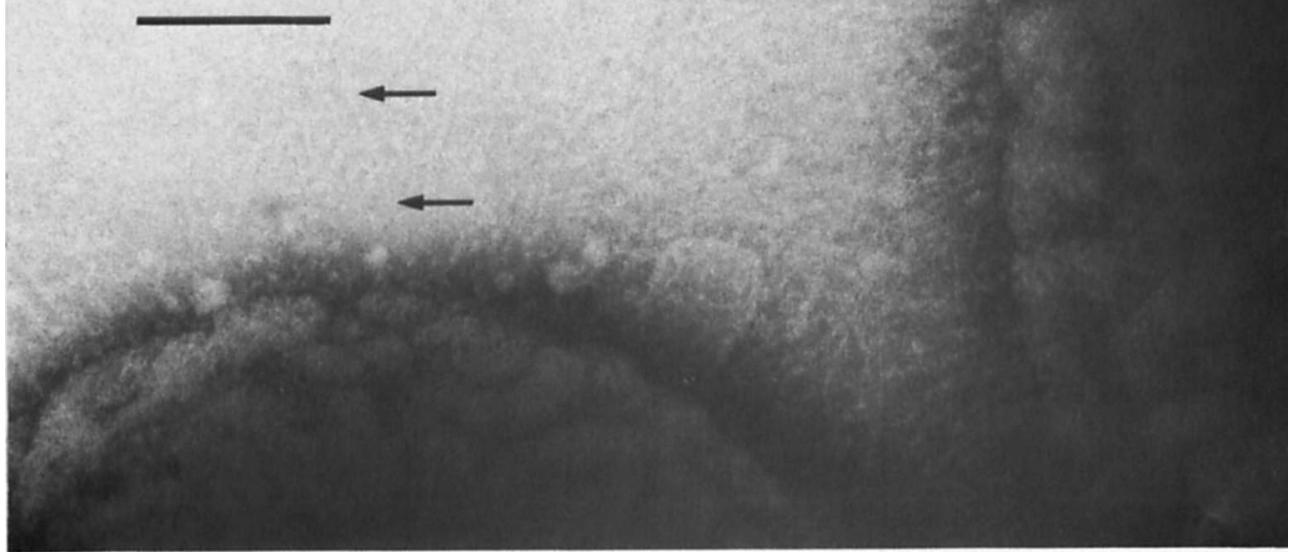



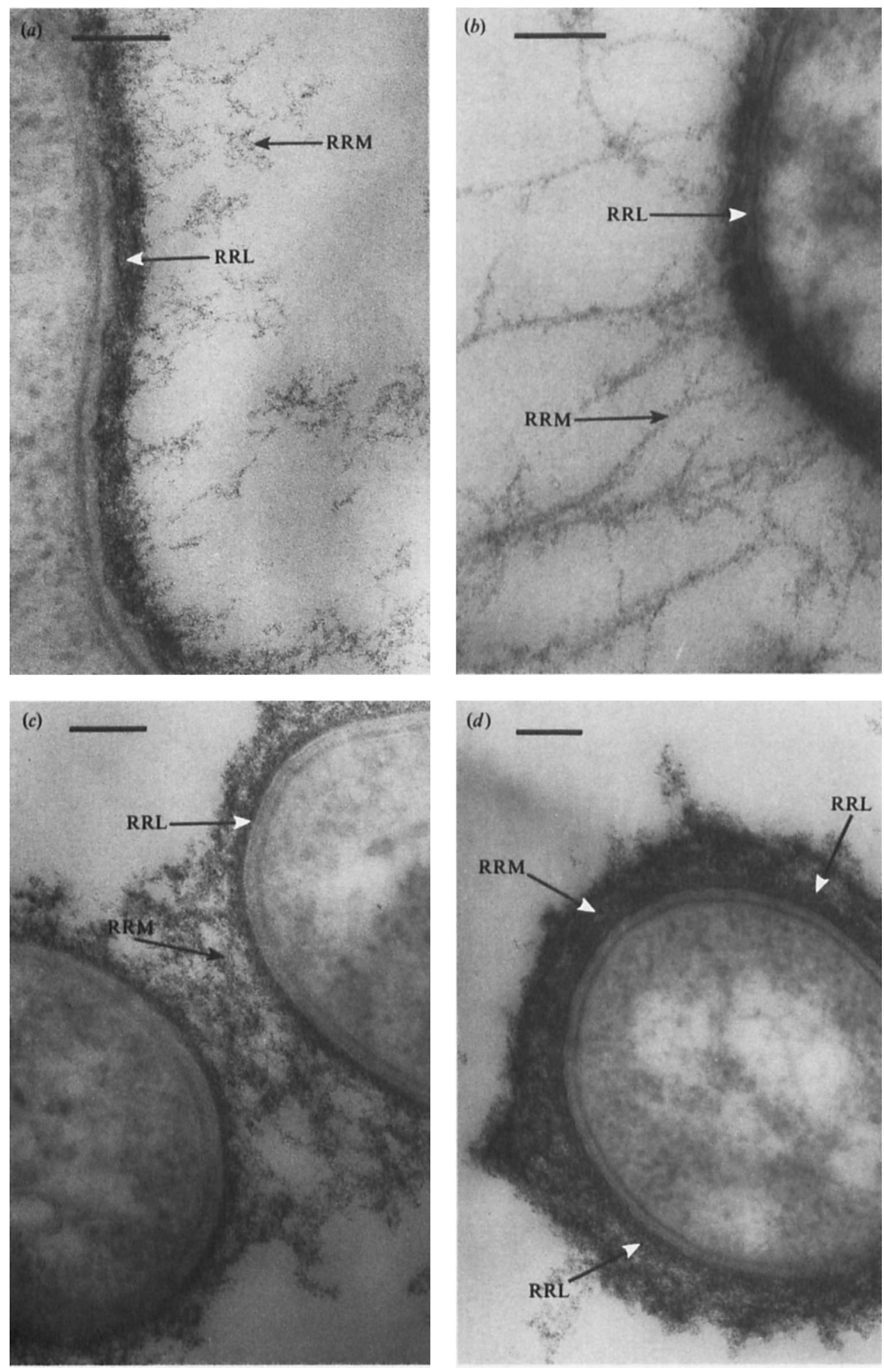
Table 1. Patterns of reactivity of strains of B. intermedius with $m A b s$

\begin{tabular}{ccccccc} 
& \multicolumn{4}{c}{ Reaction with mAb: } \\
\cline { 2 - 5 } Serogroup & 37BI6.1 & $38 \mathrm{BI} 1$ & $39 \mathrm{BI1.1}$ & $40 \mathrm{BI3.2}$ & Strains in serogroup \\
I & + & + & + & + & BH 20/30, MUI 1, MUI 32, MUI 36, MUI 65 \\
II & + & + & + & - & BH 18/23, MUI 4, MUI 15, MUI 21, MUI 24 \\
III & + & + & $--^{*}$ & - & MUI 37, MUI 41, MUI 44, MUI 57, MUI 77
\end{tabular}

* The weakly reacting antigen described by Gmür \& Guggenheim (1983) was not detected in this study.

In addition, all isolates had a $R R$ staining matrix (RRM) external to the RRL, the density and amount of which varied between strains (Fig. 2). The RRM of strains OMZ 326, MUI 21 and MUI 24 (Fig. 2a) comprised small amounts of fragmented RR stained components loosely attached to the RRL. On strains BH 18/23, OMZ 311 (Fig. 2b), MUI 1 and MUI 57 the RRM formed a delicate intercellular meshwork of sparse, branched fibres. A loose-edged matrix of intermediate density, which did not usually form distinct fibres (Fig. 2c), was observed outside the RRL of six other strains (BH 20/30, MUI 4, MUI 15, MUI 32, MUI 44 and MUI 77). Finally, most cells of strains OMZ 248 (Fig. 2d) and OMZ 327 carried a RRM which varied considerably in width but was of apparently uniform density. An RRL could be discerned on some cells, but on others it was probably obscured by the large amounts of external RRM. No layers comparable to the RRL or RRM were seen external to the outer membrane on poststained control preparations.

It is not known whether the RRM represents the fibrils or capsules of these strains. The fibrillar structures do not appear to be preserved by RR. For example, the RRM of strain MUI 32 (Fig. 2c) has no fibrillar structure when compared with the negative stain of the same strain (Fig. 1b).

\section{ELISA}

Gmür \& Wyss (1985) found that $B$. intermedius strains belong to one of three serogroups, as assessed by their reaction patterns with four $\mathrm{mAbs}$. They had previously determined that strains OMZ 248, OMZ 311, and OMZ 326 belong to serogroup I (positive reactions with all four $\mathrm{mAbs}$ ), OMZ 277 to serogroup II (positive reactions with $\mathrm{mAb} 37, \mathrm{mAb} 38$ and $\mathrm{mAb39}$ ), and strains OMZ 227 and OMZ 327 to serogroup III. B. intermedius in serogroup III were described by Gmür \& Wyss as reacting strongly with $\mathrm{mAb} 37$ and $\mathrm{mAb} 38$, negatively with mAb40, and very weakly with a great excess of mAb39 (determined spectrophotometrically). This weak reaction of $\mathrm{mAb} 39$ with strains OMZ 227 and OMZ 327 was not detected visually by our ELISA technique using an antibody dilution of $1 / 2$. Any strains having the same reactivity pattern as isolates OMZ 227 and OMZ 327 were placed with them in serogroup III.

The remaining fifteen isolates of $B$. intermedius divided evenly between the three serogroups (Table 1). The titres against $\mathrm{mAb} 37$ and $\mathrm{mAb} 38$ ranged from $1 / 640$ to $1 / 10240$. Against mAb39 the range was $1 / 160$ to $1 / 5120$. Strains BH $18 / 23$, MUI 4 and MUI 15 had relatively low titres against this antibody (1/160 to $1 / 320)$, although the colour reaction in the ELISA test was strong. Finally, titres against mAb40 ranged from 1/1280 to $1 / 10240$.

Strains with similar morphology, either after negative staining with $1 \%$ methylamine tungstate or after staining with RR, were not found in the same serogroup, indicating that these structures may not bear the antigens used in serogrouping.

Fig. 2. B. intermedius isolates after fixation, staining with RR, and thin sectioning. (a) B. intermedius MUI 24 carries a distinct, thick RRL adjacent to the outer membrane, with small amounts of fragmented RRM loosely attached to it. (b) B. intermedius OMZ 311 is a laboratory strain whose RRM forms into fine fibrous processes extending away from the narrow RRL. (c) B. intermedius MUI 32. A loose edged RRM of intermediate density, which does not form fibrous processes, can be seen external to the RRL. $(d) B$. intermedius OMZ 248 carries a dense RRM of variable thickness which partially obscures the RRL beneath it. All bar markers represent $100 \mathrm{~nm}$. 

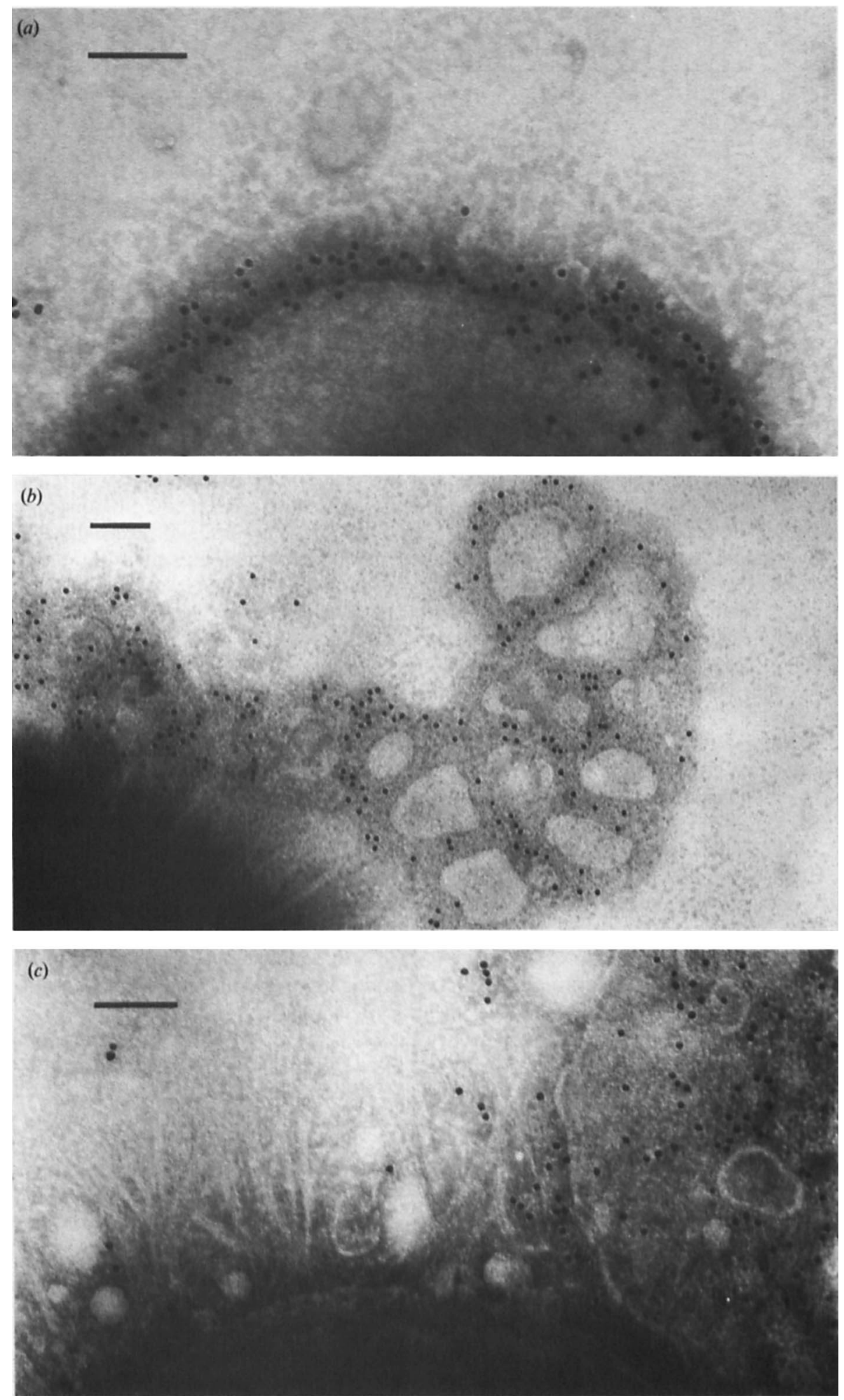


\section{Immunonegative staining}

Nine strains of $B$. intermedius were used to localize the antigens recognized by the four mAbs. Controls in which $\mathrm{mAb}$ was replaced by buffer had only a few isolated gold particles randomly scattered over the grids. Strains which did not react in the ELISA test with mAb39 or mAb40 were also included as negative controls. No non-specific binding of mAb39 took place. However, with all strains the distribution of $\mathrm{mAb} 40$ was similar regardless of the ELISA result: gold particles were spread diffusely and non-specifically in wide areas around the bacterial cells. Therefore the antigen recognized by $\mathrm{mAb} 40$ could not be localized.

The antigens recognized by $\mathrm{mAb} 37$ and $\mathrm{mAb} 39$ had similar distributions. These antibodies had high affinities for components on the cell surface (Fig. $3 a$ ) and extracellular vesicles (Fig. $3 b$ ). Neither antibody labelled fibrillar components. All cells within a population were labelled by the mAbs, although the amount of label per cell varied.

When isolates were reacted with mAb38 gold label was rarely associated with the cell surface. Whole cells were labelled with only a few gold particles, whereas mAb38 had greatest affinity for disrupted cells (Fig. $3 c$ ). In the areas surrounding bacterial cells gold label was seen on amorphous extracellular material and cell debris, and on some extracellular vesicles.

\section{DISCUSSION}

All 21 strains of $B$. intermedius examined in this study carried fibrils. The term fibril was first introduced to describe the surface structures seen on both oral streptococci (Handley et al., 1984, 1985) and Bacteroides spp. (Handley \& Tipler, 1986) that were distinct from fimbriae.

Other studies have found strains of $B$. intermedius that apparently lacked surface structures (Woo et al., 1979; Yamamoto et al., 1982). This could be due to the negative stain used. This study showed that ammonium molybdate, which was used by Woo et al. (1979), failed to reveal fibrils on some strains which were fibrillar when stained with methylamine tungstate. Yamamoto et al. (1982) observed branched 'pili-like' structures on more strains of $B$. intermedius after shadowing than on negatively stained preparations. This suggests that the negative staining technique may have been at fault. In addition, the strains included in these earlier studies were classified as $B$. melaninogenicus subsp. intermedius, which has subsequently been divided into Bacteroides corporis and B. intermedius (Johnson \& Holdeman, 1983).

The results of this study do not confirm those of Okuda et al. (1981), who examined a range of Bacteroides species and stated that surface structures were remarkably consistent among representative strains of each species or subspecies. Although all strains of $B$. intermedius in this study carried fibrils, their density, length and morphology varied considerably between strains. In addition, most of the fresh clinical isolates carried much more easily resolvable fibrils than those on the majority of laboratory isolates. This difference may be due to the repeated subculture and long-term storage of the laboratory isolates. The bacterial capsule, or glycocalyx, can be lost or changed with in vitro passage (Kasper et al., 1980; Costerton et al., 1981) and the same may be true of fibrils.

Alternatively, as the clinical strains were isolated from a limited geographical area, it is possible that the isolation rates of certain fibrillar types may vary geographically, in the same way that Escherichia coli lipopolysaccharide and capsular types are known to vary (Grüneberg $e t$ al., 1968; Sarff et al., 1975).

Extracellular vesicle production by the strains of $B$. intermedius examined in this study increased with increasing incubation time. Previous studies have described the production of extracellular vesicles by Bacteroides spp. (Listgarten \& Lai, 1979; Handley \& Tipler, 1986;

Fig. 3. Immunonegative staining of $B$. intermedius with mAbs attached to a $10 \mathrm{~nm}$ gold immunoconjugate. (a) mAb37 bound to the cell surface of $B$. intermedius OMZ 277 beneath the layer of peritrichous fibrils. (b) mAb39 labelling extracellular vesicles of $B$. intermedius OMZ 248. (c) mAb38 reacted with $B$. intermedius $\mathrm{BH} 18 / 23$. Little labelling of whole cells took place but the antibody had a high affinity for disrupted cell contents and cell debris. All bar markers represent $100 \mathrm{~nm}$. 
McKee et al., 1986; Grenier \& Mayrand, 1987). This phenomenon may be widespread among Gram-negative bacteria, as it has been described in other genera (Knox et al., 1966; Hoekstra et al., 1976; Lai et al., 1981; Thompson et al., 1985). Increased vesicle production under conditions of growth limitation or environmental stress has also been described previously (Knox et al., 1966; Thompson et al., 1985; McKee et al., 1986). It has been suggested that vesicles carry proteases and other toxic materials, and may thus be potential virulence factors (Nowotny et al., 1982; Thompson et al., 1985; Grenier \& Mayrand, 1987; Mayrand \& Holt, 1988). Although $B$. intermedius has been shown to produce some proteolytic enzymes (Lantz et al., 1985; van Steenbergen \& de Graaff, 1986) the role of vesicle production by this species is unknown.

Structural heterogeneity of the RR staining components external to the cell wall of $B$. intermedius has been reported previously. Yamamoto et al. (1982) described two types of RR stained structure; an electron dense layer adjacent to the outer membrane and a fibrous meshwork which formed an intercellular matrix, structures which resembled the RRL and RRM described in this study. Yamamoto et al. (1982) reported that strains of B. intermedius carried either or both of these structures, three of their strains having no electron dense layer adjacent to the outer membrane. However, in the present study all of the 15 strains examined carried an RRL, and all had an RRM of variable density external to this layer.

Other studies have described an electron lucent layer between the outer membrane and the RRL of $B$. intermedius isolates which had been grown on agar (Woo et al., 1979; Okuda et al., 1981). Such a layer was not observed on any of the 15 strains examined in this study, nor on any examined by Yamamoto et al. (1982), all of which were grown in broth.

The dense, $40 \mathrm{~nm}$ thick RRL outside the cell wall of Bacteroides fragilis has been called a capsule (Kasper, 1976; Kasper et al., 1977; Mansheim \& Kasper, 1977). The use of this term to describe the RRL of the $B$. intermedius strains examined in this study would be confusing, as the RRL could not account for the wide capsules seen on these strains in the light microscope after staining with Indian ink. The RRM external to the RRL observed on these strains may be responsible for the Indian ink exclusion zone. However, comparative measurements on capsules and RRMs cannot be used to establish this, as many capsular polysaccharides collapse when stained with RR unless they are first stabilized with specific antibodies (Bayer \& Thurow, 1977; Lambe et al., 1984). The term glycocalyx has been used to describe all structures such as capsules, RRLs and RRMs which surround bacterial cells (Costerton et al., 1981), and use of this term may be less confusing until more is known about the biochemical identity of the surface structures of $B$. intermedius.

So far the relationship between the capsule seen by light microscopy, the RRM seen after sectioning and fibrils seen by negative staining of whole cells is unknown. Although there was no correlation between the morphology of the RRM and the morphology of fibrils on the strains of $B$. intermedius examined in this study, it is possible that the two are the same cellular component. The fibrils found on Streptococcus salivarius HB are glycoproteins (Weerkamp \& Jacobs, 1982) that can be seen by both negative staining with $1 \%$ methylamine tungstate and by RR staining followed by thin sectioning (Handley et al., 1988). Preliminary results in this laboratory have shown that the fibrils of $B$. intermedius strains may contain protein in addition to polysaccharide, as they can be removed by trypsin treatment of whole cells.

The presence of a RRL adjacent to the cell wall may be quite common in both Gram-positive and Gram-negative bacteria. It has been observed on B. fragilis and Bacteroides ovatus (Reid \& Patrick, 1984; Patrick et al., 1986), on Streptococcus salivarius (Handley et al., 1988), as well as on Streptococcus sanguis (Hesketh et al., 1987) and Streptococcus milleri strains (P. S. Handley, unpublished data).

Since RR stains polyanions of high charge density (Luft, 1971) the $B$. intermedius strains carry a matrix of charged polysaccharide outside the cell wall which may function in adhesion or interbacterial coaggregation. Considerable strain to strain variation was seen in the morphology of the RR stained layers, as well as in the fibrils, of the strains examined in this study. This may indicate considerable biochemical variation in the outer layer of strains of $B$. intermedius, and future studies may also reveal corresponding functional variations.

Serologically, B. intermedius isolates are heterogeneous (Gmür and Wyss, 1985; Nakazawa et 
$a l .$, 1988). Using techniques of biochemical analysis, Gmür \& Wyss (1985) suggested that the antigens recognized by $\mathrm{mAb} 37, \mathrm{mAb} 38, \mathrm{mAb} 39$ and $\mathrm{mAb} 40$ are located on the outer membrane or in the layer covering this structure. The immunonegative staining in this study showed that none of the $\mathrm{mAbs}$ was directed against the fibrillar layer, which was surprising considering the density of this layer on the immunizing strain, OMZ 248. If this proves to be due to a lack of immunogenicity of this outer fibrillar layer of $B$. intermedius, it may be a distinct advantage in evading host defences in vivo.

It has been suggested that the antigens recognized by mAb37 and mAb39 may be found in the polysaccharide portions of different lipopolysaccharide molecules (Gmür \& Wyss, 1985). Immunonegative staining supported this proposal, as these two mAbs labelled the cell surface, beneath the fibrillar layer, and the surfaces of extracellular vesicles.

Gmür \& Guggenheim (1983) found that the antigen recognized by mAb38 was expressed on all saccharolytic black-pigmented Bacteroides strains tested. Biochemical studies indicated that this antigen is a protein with lipophilic groups, which was assumed to be associated with the outer membrane and could be extracted with it (Gmür \& Wyss, 1985). In this study immunonegative staining revealed only small amounts of this antigen exposed on the cell surface. Most mAb38 bound to disrupted cell contents and to cell debris. Thus, as the antigen recognized by this antibody can be extracted with the outer membrane, it is possible that it is usually found on the inner leaflet of the outer membrane and is only rarely expressed on the cell surface. The increased amount of the antigen recognized by mAb38 detected here after cell lysis may also help to explain the uneven expression of the antigen found by Gmür \& Wyss (1985) when examining strains of $B$. intermedius by immunofluorescence. They found that, for some strains, a minority of cells showed strong immunofluorescence with mAb38, while the majority of cells appeared unlabelled. Other strains, which presumably lysed more readily, stained homogeneously.

There are two genotypes of $B$. intermedius exhibiting less than $45 \%$ DNA homology (van Steenbergen et al., 1982; Johnson \& Holdeman, 1983), but which are metabolically very similar. It has been suggested that the two genotypes represent different species (Johnson \& Holdeman, 1983), which may differ in their capacity to cause periodontal disease (Moore et al., 1983, 1985). Phenotypic markers have not previously been available to distinguish between them. There is evidence to suggest that the antigen recognized by mAb40 may be a marker, being carried only by strains of genotype I (Gmür \& Wyss, 1985). In this study immunonegative staining could not localize this antigen, and the structural study has not been able to identify structural subgroups which could correlate with the two different genotypes. However, functional differences may be revealed in future studies.

This work was supported by MRC grant no. G8609111SB.

\section{REFERENCES}

Bayer, M. E. \& Thurow, H. (1977). Polysaccharide capsule of Escherichia coli. Microscope study of its size, structure and sites of synthesis. Journal of Bacteriology 130, 911-936.

Costerton, J. W., IRvin, R. T. \& ChenG, K.-J. (1981). The bacterial glycocalyx in nature and disease. Annual Review of Microbiology 35, 299-324.

GMÜR, R. \& GUGGeNHEIM, B. (1983). Antigenic heterogeneity of Bacteroides intermedius as recognized by monoclonal antibodies. Infection and Immunity 42, 459-470.

GMÜR, R. \& WYSS, C. (1985). Monoclonal antibodies to characterize the antigenic heterogeneity of Bacteroides intermedius. In Monoclonal Antibodies against Bacteria, vol. 1, pp. 91-119. Edited by A. J. L. Macario \& E. Conway de Macario. London: Academic Press.
Grenier, D. \& MaYrand, D. (1987). Functional characterization of extracellular vesicles produced by Bacteroides gingivalis. Infection and Immunity $\mathbf{5 5}$, 111-117.

Grüneberg, R. N., LeiGh, D. A. \& Brumfitt, W. (1968). Escherichia coli serotypes in urinary tract infection; studies in domiciliary, antenatal and hospital practice. In Urinary Tract Infection, pp. 6879. Edited by F. O'Grady \& W. Brumfitt. Oxford: Oxford University Press.

Handley, P. S. \& TiPleR, L. S. (1986). An electron microscope survey of the surface structures and hydrophobicity of oral and non-oral species of the bacterial genus Bacteroides. Archives of Oral Biology 31, 325-335.

Handley, P. S., Carter, P. L. \& Fielding, J. (1984). Streptococcus salivarius strains carry either fibrils or 
fimbriae on the cell surface. Journal of Bacteriology 157, 64-72.

Handley, P. S., Carter, P. L., Wyatt, J. E. \& HESKETH, L. M. (1985). Surface structures (peritrichous fibrils and tufts of fibrils) found on Streptococcus sanguis strains may be related to their ability to coaggregate with other oral genera. Infection and Immunity 47, 217-227.

Handley, P. S., Hargreaves, J. \& Harty, D. W. S. (1988). Ruthenium red staining reveals surface fibrils and a layer external to the cell wall in Streptococcus salivarius HB and adhesion deficient mutants. Journal of General Microbiology 134, 31653172.

Hesketh, L. M., Wyatt, J. E. \& Handley, P. S. (1987). Effect of protease on cell surface structure, hydrophobicity and adhesion of tufted strains of Streptococcus sanguis biotypes I and II. Microbios $\mathbf{5 0}$ 131-145.

Hoekstra, D., Van der laAN, J. W., De LeiJ, L. \& Witholt, B. (1976). Release of outer membrane fragments from normally growing Escherichia coli. Biochimica et biophysica acta 455, 889-899.

JoHNSON, J. L. \& Holdeman, L. V. (1983). Bacteroides intermedius comb. nov. and descriptions of Bacteroides corporis $\mathrm{sp}$. nov. and Bacteroides levii $\mathrm{sp}$. nov. International Journal of Systematic Bacteriology 33, 15-25.

KASPER, D. L. (1976). Chemical and biological characterization of the lipopolysaccharide of Bacteroides fragilis subspecies fragilis. Journal of Infectious Diseases 134, 59-66.

Kasper, D. L., Hayes, M. E., Reinap, B. G., Craft, F. O., ONDERDONK, A. B. \& POCK, B. F. (1977). Isolation and identification of encapsulated strains of Bacteroides fragilis. Journal of Infectious Diseases 136, 75-81.

KaSPER, D. L., ONDERdonK, A. B., ReinaP, B. G. \& LINDBERG, A. A. (1980). Variation of Bacteroides fragilis with in vitro passage: presence of an outer membrane-associated glycan and loss of capsular antigen. Journal of Infectious Diseases 142, 750-756.

KNox, K. W., VeSK, M. \& Work, E. (1966). Relation between excreted lipopolysaccharide complexes and surface structures of a lysine-limited culture of Escherichia coli. Journal of Bacteriology 92, 12061217.

Lai, C.-H., Listgarten, M. A. \& Hammond, B. F. (1981). Comparative ultrastructure of leukotoxic and non-leukotoxic strains of Actinobacillus actinomycetemcomitans. Journal of Periodontal Research 16, 379 389.

Lambe, D. W., Mayberry-Carson, K. J., Ferguson, K. P. \& Costerton, J. W. (1984). Morphological stabilization of the glycocalyx of 23 strains of 5 Bacteroides species using specific antisera. Canadian Journal of Microbiology 30, 809-819.

LantZ, M. S., Switalski, L. M., Kornman, K. S. \& HööK, M. (1985). Bacteroides intermedius binds fibrinogen. Journal of Bacteriology 163, 623-628.

Listgarten, M. A. \& LAI, C.-H. (1979). Comparative ultrastructure of Bacteroides melaninogenicus subspecies. Journal of Periodontal Research 14, 332-340.

LOESCHE, W. J., HOCKETT, R. N. \& SYED, S. A. (1972). The predominant cultivable flora of tooth surface plaque removed from institutionalized subjects. Archives of Oral Biology 17, 1311-1325.
LuFT, J. H. (1971). Ruthenium red and violet. I. Chemistry, purification, methods of use for electron microscopy and mechanism of action. Anatomical Record 171, 347-368.

McKee, A. S., McDermid, A. S., Baskerville, A., Dowsett, A. B., Ellwood, D. C. \& MARSh, P. D. (1986). Effect of hemin on the physiology and virulence of Bacteroides gingivalis W50. Infection and Immunity 52, 349-355.

MANSheim, B. J. \& KasPer, D. L. (1977). Purification and immunochemical characterization of the outer membrane complex of Bacteroides melaninogenicus subspecies asaccharolyticus. Journal of Infectious Diseases 135, 787-799.

MaYRAND, D. \& Holt, S. C. (1988). Biology of asaccharolytic black-pigmented Bacteroides species. Microbiological Reviews 52, 134-152.

Moore, W. E. C., Holdeman, L. V., Cato, E. P., SMIBERT, R. M., BURMEISTER, J. A. \& RANNEY, R. R. (1983). Bacteriology of moderate (chronic) periodontitis in mature adult humans. Infection and Immunity 42, 510-515

Moore, W. E. C., Holdeman, L. V., Cato, E. P., Smibert, R. M., Burmeister, J. A., Palcanis, K. G. \& RANNEY, R. R. (1985). Comparative bacteriology of juvenile periodontitis. Infection and Immunity 48 , 507-519.

Nakazawa, F., Zambon, J. J., Reynolds, H. S. \& GENCO, R. J. (1988). Serological studies of oral Bacteroides intermedius. Infection and Immunity 56, 1647-1651.

Nowotny, A., Behling, U. H., Hammond, B., LAI, C.-H., Listgarten, M., Pham, P. H. \& Sanavi, F. (1982). Release of toxic microvesicles by Actinobacillus actinomycetemcomitans. Infection and Immunity 37, 151-154.

OKudA, K., Slots, J. \& Genco, R. J. (1981). Bacteroides gingivalis, Bacteroides asaccharolyticus and Bacteroides melaninogenicus subspecies: cell surface morphology and adherence to erythrocytes and human buccal epithelial cells. Current Microbiology 6, 7-12.

Otтow, J. C. G. (1975). Ecology, physiology and genetics of fimbriae and pili. Annual Review of Microbiology 29, 79-108.

Patrick, S., ReId, J. H. \& Coffey, A. (1986) Capsulation of in vitro and in vivo grown Bacteroides species. Journal of General Microbiology 132, 1099 1109.

Reid, J. H. \& Patrick, S. (1984). Phagocytic and serum killing of capsulate and non-capsulate Bacteroides fragilis. Journal of Medical Microbiology 17, 247-257.

REYNOLDS, E. S. (1963). The use of lead citrate at high $\mathrm{pH}$ as an electron opaque stain in electron microscopy. Journal of Cellular Biology 17, 208-212.

SARFF, L. D., McCracken, G. H., SChiffer, M. S., Glode, M. P., RobBINS, J. B., ØRSKOV, I. \& ØRSKOV, F. (1975). Epidemiology of Escherichia coli $\mathrm{Kl}$ in healthy and diseased newborns. Lancet i, 1099-1104.

SLOTS, J. (1979). Subgingival microflora and periodontal disease. Journal of Clinical Periodontology 6, 351382.

SLOTS, J. (1986). Bacterial specificity in adult periodontitis - a summary of recent work. Journal of Clinical Periodontology 13, 912-917.

SLOTS, J. \& GENCO, R. J. (1984). Black-pigmented 
Bacteroides species. Capnocytophaga species, and Actinobacillus actinomycetemcomitans in human periodontal disease: virulence factors in colonization, survival and tissue destruction. Journal of Dental Research 63, 412-421.

van Steenbergen, T. J. M. \& DE GraAfF, J. (1986). Proteolytic activity of black-pigmented Bacteroides strains. FEMS Microbiology Letters 33, 219-222.

VAN Steenbergen, T. J. M., VlaAnderen, C. A. \& DE GraAFF, J. (1982). Deoxyribonucleic acid homologies among strains of Bacteroides melaninogenicus and related species. Journal of Applied Bacteriology 53, 269-276.

Thompson, S. S., Naidu, Y. M. \& PestKa, J. J. (1985). Extracellular localisation of an extracellular protease in Pseudomonas fragi by using the peroxidaseantiperoxidase reaction. Applied and Environmental Microbiology 50, 1038-1042.
WeErKamp, A. H. \& Jacobs, T. (1982). Cell wall protein antigens of Streptococcus salivarius: purification, properties, and function in adherence. Infection and Immunity 38, 233-242.

Woo, D. D. L., Holt, S. C. \& Leadbetter, E. R. (1979). Ultrastructure of Bacteroides species: Bacteroides asaccharolyticus, Bacteroides fragilis, Bacteroides melaninogenicus subspecies melaninogenicus, and $B$. melaninogenicus subspecies intermedius. Journal of Infectious Diseases 139, 534-546.

Yamamoto, A., Takahashi, M., Takamori, K. \& SASAKI, T. (1982). Ultrastructure of the outer membrane surface of black-pigmented Bacteroides isolated from the human oral cavity. Bulletin of the Tokyo Dental College 23, 47-60.

Zambon, J. J., ReYnolds, H. S. \& Slots, J. (1981). Black-pigmented Bacteroides spp. in the human oral cavity. Infection and Immunity 32, 198-203. 